\title{
UM LUGAR NA HISTÓRIA PARA A DIDÁTICA DA HISTÓRIA
}

\section{A PLACE IN HISTORY FOR HISTORY DIDACTICS}

\author{
Luis Fernando Cerri ${ }^{1}$
}

\begin{abstract}
RESUMO: Esse texto almeja oferecer uma leitura breve sobre as mudanças na Didática da História, delinear um novo conceito de Didática da História que incorpora as mudanças havidas no período recente e a situação atual do debate e, a partir de exemplo, delinear algo do campo, objeto, métodos e objetivos da Didática da História dentro da pesquisa histórica. Argumenta-se que a disciplina, que compõe a propedêutica do profissional de História, deve também constituir um espaço na formação e nos estudos pós-graduados em História, consideradas as suas especificidades: produção de textos históricos, mas não historiográficos, empiria diversa tratada com metodologia igualmente diversificada e capacidade de aportar à História uma reflexão sobre si mesma e seus critérios de validade dos enunciados a partir de "fora" do âmbito específico da ciência.
\end{abstract}

Palavras-chave: Didática da história. Formação do historiador. Pesquisa histórica.

\begin{abstract}
This text aims to offer a brief reading about the changes at the History Didactics, to outline a new History Didactics concept that embodies the changes that happened recently and the current situation of the debate and, from an example, to outline some of the field, object, methods and objectives of History Didactic inside the historical research. One argues that the discipline, that makes up the propaedeutic of the History professional, shall also make up a space into training and graduate studies in History on considering its specificities: production of historic, but not historiographical texts, distinct empirics treated by an equally diversified methodology and ability to bring into History a reflection about itself and its criteria of validation of statements from "outside" the specific range of the science.
\end{abstract}

Keywords: History didactics. Historian training. Historical research.

\footnotetext{
1 Professor Associado da Universidade Estadual de Ponta Grossa (UEPG). Doutor em Educação pela Universidade Estadual de Campinas (UNICAMP).
} 


\section{Primeiras palavras ${ }^{2 * *}$}

Quando usamos a expressão "Didática da História", quais são as primeiras imagens que nos vêm à mente? Para a maioria daqueles formados na academia até os anos 1980 e, mesmo, 1990, provavelmente as imagens se referem a planos de aula, técnicas de ensino, uso do quadro de giz e do retroprojetor (ou do episcópio para os jovens há mais tempo), impostação de voz, domínio de classe e elementos assemelhados. O conhecimento histórico aí fica secundário: poderia ser qualquer outro! É possível que, para os mais jovens, outras imagens e conteúdos se manifestem mais prontamente, com reflexões elaboradas sobre o processo de ensino e aprendizagem em sala de aula, sobre aspectos das teorias do currículo ou, ainda, estudos quanto aos aspectos sociológicos, antropológicos e psicológicos do fenômeno social do ensino e da aprendizagem. É possível, ainda, que a atual geração de professores em formação contemple as mesmas imagens que nós e a geração que nos antecedeu. A primeira conclusão que podemos tirar desse exercício sem muito rigor é que "Didática" acaba sobrepondo-se a "da História". Por que é assim?

Uma visão tradicional sobre a história, tal como essa, não permitiria conceber a Didática da História como um campo legítimo e profícuo de pesquisa histórica. O objetivo principal deste texto é traçar a ponte entre esses dois pontos: uma visão datada de Didática de História e a Didática da História como uma disciplina no âmbito da produção de conhecimento histórico, destinada a investigar os processos formativos que envolvem a nossa disciplina. A matéria prima dessa ponte é uma recuperação dos debates e conceitos que foram sendo elaborados nos últimos 30 a 40 anos, ao redor do mundo, entre os historiadores envolvidos com o ensino da História e alguns exemplos que permitam vislumbrar o panorama de possibilidades de pesquisa e de formação profissional, envolvendo as reflexões sobre ensino e aprendizagem de história.

Estamos em plena transição entre um paradigma da Didática da História entendida como disciplina voltada à especificidade do ensinar História na escola, uma disciplina do "como", para um novo paradigma da Didática da História, em

\footnotetext{
2 **Esse texto utiliza, ao final, dados que foram produzidos pelo projeto Jovens e a História, financiado, em diferentes editais, pelo CNPq e pela Fundação Araucária.
} 
que se agregam muitas perguntas ao "como": "por quê", "para quem", "para quê", "desde quando", "a partir de quê", entre outras tantas indagações.

Com esse texto, pretende-se: a) oferecer uma leitura breve sobre as mudanças na Didática da História; b) delinear um novo conceito de Didática da História que incorpora as mudanças havidas no período recente e a situação atual do debate e, c) a partir de exemplo, delinear algo do campo, objeto, métodos e objetivos da Didática da História dentro da pesquisa histórica, a qual, defenderemos, tem um caráter formativo importante nos cursos de formação de professores, mas também um papel importante e um lugar a ser preenchido na pesquisa e na pós-graduação em história.

\section{Notas históricas sobre a Didática da História}

É forçoso reconhecer que, por muito tempo, não houve Didática da História, na mesma proporção em que não houve Teoria da História ou estudos historiográficos. A disciplina História como a conhecemos, nascida no século XIX (FURET, 1986), apenas por estudos individuais e isolados começava a se debruçar sobre si própria, preocupada que estava em dizer sobre o passado, bem como participar do esforço conjunto para produzir a nação nas mentes e nos corações. No Brasil, por exemplo, esse esforço era partilhado com pintores (vide FONSECA, 2001), literatos (MATTOS, 2000), músicos (RABELO, 2013) e outros. Teorizar sobre o que se fazia, em termos de método de trabalho, de significado e propósito, cotejando com a filosofia, de formas e funções, constituiu-se mais como uma preocupação no fundo da cena que com disciplinas internas à área de conhecimento.

O ensino escolar de História surge no contexto da construção deliberada de identidade nacional nos processos de superação do Antigo Regime. No caso do Brasil, em que a História pesquisada e ensinada se constitui no seio do Império (e no caso da disciplina escolar, segundo Gasparello, 2004, p. 68, por ordem direta de D. Pedro II), trata-se de produzir brasileiros. Numa monarquia constitucional, a História não deixa de ser o produto liberal e iluminista, a exemplo do que se passa em alguns países europeus do século XIX, ainda que repercutindo o 
confronto entre conservadores e liberais (BITTENCOURT, 1993). Esta marca de nascença da sociedade em que primeiro se inseriu vai caracterizar, em maior ou menor grau, o ensino de História até a atualidade. Guardadas as semelhanças, o ensino de História não é um fato homogêneo e de igual significado nos diferentes países em que se insere. No Brasil, o surgimento em uma sociedade escravista e aristocrática criará uma espécie de "código genético", uma marca de nascença que resiste ao combate que a ela se fará, principalmente no final do século XX. Não se trata de recorrer a organicismos, mas de produzir uma figura de linguagem, uma metáfora, para delinear uma hipótese consistente sobre as permanências do ensino escolar da História.

Os fatores políticos e sociais que levaram ao surgimento da história ensinada - nacionalismo, linearidade temporal, fatos como o centro do ensino, regime moderno de verdade, método catequético de perguntas e respostas (BRUTER, 2003, p. 177), entre outros - terminaram por constituir uma representação social e um conjunto de concepções e práticas que tendem a se replicar em cada reprodução de normas, currículos, planejamentos e situações concretas de sala de aula. Deste modo, a inovação educacional nessa área bate-se contra uma inércia de repouso com um poder de permanência importante, que não raro dilui e absorve a mudança na sua superfície, mantendo o cerne tal como era antes. Essa inércia de repouso contribui para explicar porque, mesmo com uma formação bastante contemporânea, crítica e ilustrada, professores formados em história são atraídos para acomodar-se aos cânones estabelecidos secularmente em sua profissão, assim como explica que reformas curriculares com ideias revolucionárias virem meras lembranças em menos de uma década, apesar de todo o investimento financeiro, intelectual, de tempo e de recursos humanos envolvidos. Esse olhar "pessimista" não deveria ter o poder de negar os esforços por mudança, mas tão somente de reconhecer a dimensão das forças em jogo: não são como exércitos que se batem com chances parecidas, mas mais propriamente como a água mole contra a pedra dura do ditado popular.

Aquele código (que poderíamos chamar, junto com Cuesta Fernandez (1997) - de código disciplinar, e classificar, com Raymond Willians (1979), entre os processos de tradição seletiva) é caracterizado, no Brasil das transições "pacíficas" e pelo alto, pela busca de uma identidade assimiladora, unificadora, 
colaboracionista, ao contrário de identidades mobilizadoras, por exemplo, para a guerra, como é o caso seminal de França e Alemanha, cujos códigos disciplinares ficaram marcados pelo contexto da disputa territorial na fronteira dos dois países (CITRON, 1987, p. 18).

Socialmente, espera-se do ensino de história o fornecimento de um conjunto de conhecimentos que ao cidadão cumpra dominar, o qual interfira positivamente na qualidade da sua cidadania. Assim, determinadas coisas, acontecimentos e pessoas, se bem compreendidas e guardadas - o que envolve também um elemento afetivo - propiciariam ou ajudariam a propiciar um bom cidadão, comprometido com os objetivos de sua pátria. Portanto, uma determinada visão do ensino da História, que hoje tomamos como simplista, espera que este leve o aluno-cidadão a saber as orações cívicas - os hinos - e os nomes dos principais santos cívicos, os próceres. Mais especializadamente, espera-se que o ensino de História contribua de modo decisivo para a formação do cidadão em nossas sociedades, colaborando para o surgimento e consolidação do espírito público, do patriotismo e do respeito aos interesses e projetos coletivos, por meio da vinculação de todos a um passado comum.

\section{A virada paradigmática da Didática da História no final do século $X X$}

Dentro de uma perspectiva tradicional, do cruzamento entre temas, objetos, conteúdos, metodologias e teorias da História e da Educação podiam surgir dois, e apenas dois resultados: a História da Educação ou a Didática da História entendida restritamente como a Metodologia do Ensino de História. Tal visão não encontra mais respaldo na atualidade, uma vez que as discussões sobre o campo de encontro ou de cruzamento entre História e Educação passaram por um momento de mudança de paradigmas que alteram o sentido da Didática da História. Esse movimento pode ser observado em diferentes lugares ao redor do mundo, num período que vai dos anos 1960 aos anos 1980, aproximadamente, em que as afirmações sobre o ensino da História são submetidas a uma crise proveniente de novas demandas sociais sobre a identidade coletiva em função do tempo. Essas demandas, assumidas e traduzidas nas universidades e escolas, 
promovem o desenvolvimento da autoconsciência do campo do ensino de História, assim como a tematização da análise crítica de suas origens, métodos, funções, relações com processos de identificação social, nacional, política, cidadã, relações com o conhecimento científico e com as disputas sociais para destacar ou esquecer memórias, personagens e grupos.

No Brasil, a maior parte do processo de mudança de paradigma da Didática da História pode ser identificado ocorrendo ao longo das disputas pela redemocratização nacional com o progressivo fim da ditadura, nos anos 1980. Afinal, o esforço das instituições educativas por submeter o ensino de história à lógica da doutrina de segurança nacional (FONSECA, 1993, p. 35), visando reproduzir ideologicamente uma pedagogia da passividade, da colaboração com as autoridades e de um patriotismo acrítico, acabou por evidenciar que conteúdos e métodos não eram dados "naturais", mas construções sociais e políticas referenciadas em parte dos sujeitos coletivos daquela conjuntura. Dessa percepção decorre, naturalmente, a crise da ideia de unicidade e de neutralidade da educação, em geral, e do ensino de história, em particular. Obviamente, não se trata de um processo tão unívoco e linear quanto esse parágrafo pode dar a entender.

Deve-se considerar que a crise de um sistema político, o qual tentou encarnar a nação, coloca em crise a própria ideia de que algum sistema específico possa representá-la, donde se insurge a perspectiva da historicidade e subjetividade dos discursos, currículos e programas estatais. Na diferenciação irreversível entre a voz da nação, a voz do Estado, a voz do governo, e a voz da coalização de grupos de interesses que constituem cada governo, abre-se a perspectiva de que tudo pode ser mudado, pois não há o que não possa ser reinventado, a educação e o ensino de História inclusos. Colabora, também, para esse repensar do ensino, o contexto de crise econômica em aprofundamento, de progressiva diluição do poder centralizado nos ditadores diante das concessões que permitem a Anistia, a retomada dos movimentos sindicais e populares, o fim do AI-5 e a reforma partidária, a proletarização e a organização sindical dos professores, bem como um contexto universitário em que se retomam o marxismo e outras teorias críticas, e se denuncia e analisa o caráter de reprodução social e ideológica da educação. Esse contexto gera, entre os subprodutos que nos 
interessam, a criação de uma identidade laboral de professores de história em busca de um ensino de história, ao mesmo tempo, para a transformação social e aprofundamento da democracia (PACIEVITCH; CERRI, 2006).

O desafio de redemocratizar também a cultura e a educação leva a um amplo processo reflexivo quanto aos conteúdos e métodos, mas também às origens, finalidades, objetivos, interfaces sociais, variáveis regionais e culturais, aspectos políticos e sociológicos envolvidos no ensino da História escolar. Percebese que, para além do escolar, o ensino e a aprendizagem não escolares são fatores decisivos.

Suzanne Citron fornece um pequeno vislumbre sobre o contexto francês no qual a escola e o ensino de história entram em crise - e, por consequência, o mundo acadêmico, responsável por entender e preparar o ensino, especialmente de história. "O ensino de história tornou-se o cimento da ideologia de integração à cultura dominante, considerada por sua vez como superior e nacional." (CITRON, 1984, p. 9). Os objetivos da história ensinada na tradição escolar, até os anos 1970, seriam "afrancesar" e "civilizar" os franceses, na França e nas colônias. Todavia, com as lutas contra a dominação colonial, a novidade passou a ser o influxo significativo de africanos, árabes e pessoas de outras origens e etnias para a França, emigrados das futuras ex-colônias francesas, e o descrédito do "nós, os gauleses" nas escolas coloniais ou recém descolonizadas. A crise do ensino de história passa a aparecer como o sintoma mais transparente na crise da cultura escolar, que gerou vigorosas reações do governo francês, incapazes, então, de perceber o fundo da questão:

\begin{abstract}
A escola, ao instituir a história como memória coletiva única, ao repelir as outras memórias sociais, permanece na lógica de um sistema de saberes pré-concebidos, 'positivos', objetivos, impostos sem levar em conta a diversidade dos jovens a formar (CITRON, 1984 , p. 11).
\end{abstract}

Nesse sentido, a autora indicava, ao contrário do senso comum convertido em visão do governo, que a crise de identidade nacional não estava colocada pela "sabotagem" do ensino de história, mas pelo processo de modernização, pelos problemas de uma sociedade pluri-étnica, por um neorracismo. 
Saddi (2014) também identifica uma situação de crise na potencialização da mudança de paradigma da Didática da História, na então Alemanha Ocidental, emergindo - envolvendo o conflito de gerações nos anos 1960 (mais agudo para um país derrotado na guerra, cf. SADDI, 2014) e o tema sensível do Holocausto apesar dos esforços dos governos alemães pós-guerra em silenciar o assunto. Trata-se do contexto que envolve a mudança paradigmática da Didática da História, discutida por Rüsen (2006).

O que parece comum, a todos os casos, é o fato de que uma dada crise de identidade coletiva precipita a disseminação de uma nova autoconsciência, da história e do ensino da história, pela qual os sujeitos passam a perceber ou considerar a equivocidade da formação que a história escolar fornece. Em outros termos, o foco da atenção passa dos desafios do ensino para as interrogações sobre a multidimensionalidade do processo de aprendizagem, passagem essa disparada pelas dúvidas quanto ao papel da disciplina escolar até o momento. Vista como formadora de uma identidade padrão desejável e incentivada socialmente, a história passa a ser cada vez mais percebida e explicada como um processo de dominação em que um grupo impõe seus padrões culturais, políticos, linguísticos, étnicos, econômicos etc., sobre outros. Sobe para o primeiro plano o paradoxo da aula de história, na colônia francesa, na África, em que o material didático ensina aos estudantes: "nós, os gauleses"; ou a sala de aula, da periferia da cidade de São Paulo, em que a professora ensina à turma, formada de migrantes nordestinos, que eles são os descendentes dos bandeirantes, a "raça de gigantes" brasileira; ou, ainda, as aulas de história, na Argentina, em que se ensina uma história nacionalista que unificaria a todos, mas que só subsiste se for escondida a fratura do país, entre os apoiadores da ditadura e as mães e avós da Praça de Maio. Obviamente, esse movimento não ocorre apenas entre os que se puseram a pensar sobre o ensino de história; pelo contrário, tratou-se de um movimento que mobilizou a História e as Ciências Humanas e Sociais num esforço de dialogar com as respectivas realidades que progressivamente iam reconhecendo as suas faces ásperas, incômodas, cortantes.

Para além das especificidades, todos esses processos envolvem pontos de ruptura em que é posta em xeque a ideia de que a História ensinada cumpre a função de transmitir uma narrativa unívoca de uma geração para outra. 0 
reconhecimento de que o ensino da História é o resultado, sempre variável, de um embate, sem resultados definitivos, entre diferentes forças sociais, suas identidades e suas visões do passado, é outra consequência desses processos. Para isso, por sua vez, acaba sendo forçoso admitir que a História - acadêmica ou científica - não monopoliza a produção de sentidos e narrativas históricas destinadas às escolas e, portanto, cabe reconhecer que essa produção resulta de fenômenos disseminados no corpo social. E é aí que o conceito de consciência histórica ganha força explicativa.

As mudanças de demandas, funções, finalidades e definições do ensino de História podem ser mais bem compreendidas através do conceito de consciência histórica (o que não implica que todas esses processos estejam submetidos ao conhecimento e concordância com esse conceito, pelo contrário). É que, quando se reflete sobre a história e seu ensino, quando se desenvolve a reflexão didática, as questões que se colocaram para os didatas da História são espontâneas, e mesmo necessárias. Em primeiro lugar, porque recolocam o ensino escolar de História na sua dimensão real, mergulhado na vida da sociedade que o produz, no intercruzamento e no inter-relacionamento entre os vários focos de produção de sentidos e narrativas históricas não acadêmicas ou não científicas. O conceito de consciência histórica dá formalidade e consistência à ideia, constituída nesses diversos processos de mudança, de que o conhecimento histórico ultrapassa a academia e constitui-se desde diversas formas, conteúdos, funções e focos de enunciação. Assim, o conhecimento histórico escolar não pode ser apenas o conhecimento acadêmico resumido ou simplificado para o público infanto-juvenil, mas um daqueles focos sociais nos quais a história é produzida em formas, conteúdos e funções próprios ao seu contexto.

Cabe, por fim, antes de passar ao próximo tópico, reconhecer que este contexto de mudanças no ensino de História não se dá separadamente das transformações nos campos da História e da Educação neste período dos anos 1960 a 1980, aproximadamente, porém não faz parte do escopo deste texto abordá-los mais detidamente.

\section{Um olhar sobre a Didática da História hoje e um esboço de conceito}


Uma reflexão é histórico-didática na medida em que investiga seu objeto sob o ponto de vista da prática da vida real, isto é, na medida em que, no que se refere ao ensino e à aprendizagem, se preocupa com o conteúdo que é realmente transmitido, com o que podia e com o que devia ser transmitido (BERGMANN, 1990, p. 29)

Assim começa o texto de Klaus Bergmann para o manual de Didática da História organizado, pelo mesmo autor e outros, em 1985, na Alemanha, e traduzido para a Revista Brasileira de História em 1990. O texto não chamou muito a atenção dos professores e pesquisadores do ensino de história naquele momento, mas, mesmo assim, significou uma referência de que a influência dos teóricos alemães sobre a Didática da História no Brasil não começa com a publicação do primeiro livro da trilogia sobre a teoria da História de Rüsen, em 2001 (ver RÜSEN, 2001, 2007a, 2007b). O texto de Bergmann ao lado de outro texto de Rüsen, primeiramente publicado em inglês, nos anos 1980, e traduzido, em 2006, originalmente para a revista Práxis Educativa (RÜSEN, 2006), reflete e divulga a ideia de virada paradigmática no conceito de Didática da História por causa do conceito de consciência histórica.

A consciência histórica pode ser definida como "a suma das operações mentais com as quais os homens interpretam a sua experiência de evolução temporal de seu mundo e de si mesmos, de tal forma que possam orientar, intencionalmente, sua vida prática no tempo" (RÜSEN, 2001, p. 57) ou ainda "o grau de consciência da relação entre o passado, o presente e o futuro" (ANGVIK, Von BORRIES, 1997, p. 403). Para esse grupo de teóricos da História, o reconhecimento de um fenômeno como a consciência histórica tem implicações importantes para a teoria da História e para o ensino da disciplina. Com esse conceito, a Didática da História não pode ser mais o conjunto de teorias e métodos voltados ao ensino, mas precisa ser uma teoria da aprendizagem histórica, superando, se quiser responder aos desafios contemporâneos, o campo restrito da metodologia de ensino (RÜSEN, 2007b, p. 88-94). Bergmann define que, nesta chave de compreensão, a Didática da História pode e deve ser tomada como uma disciplina interna à teoria da História, o que é coerente com a perspectiva de que uma reflexão teórica sobre a história se debruça, entre outros aspectos, sobre as condições históricas de produção, difusão e recepção do conhecimento histórico, 
pois isto compõe a historicidade dos estudos teóricos. Esta seria a "análise externa", ao passo que a "análise interna" se comporia da discussão dos postulados, princípios, noções e conceitos em si, tanto numa dimensão retrospectiva (uma história da historiografia) quanto em termos de síntese das reflexões nascidas das demandas da historiografia no presente.

Oldimar Cardoso (2008) sintetiza parte da discussão sobre o conceito atual de Didática da História remetendo ao conceito de saberes escolares de André Chervel que, por sua vez, desconstrói a ideia tradicional de que existiria um processo de transmissão unívoco da história acadêmica para a história escolar, o qual fosse definitivo e intrinsecamente constituinte da identidade da disciplina na escola. Porém, o conceito contemporâneo de Didática da História não prescinde da contribuição dos autores alemães para os quais, em síntese, trata-se de uma disciplina que integra a História, e cujo escopo é dado pelo estudo da consciência histórica e do desenvolvimento da cultura histórica, por sua vez, expressão da consciência histórica (CARDOSO, 2008, p. 58-59).

A perspectiva de que a Didática da História está para a história escolar como a Teoria da História está para a história dos historiadores, somada à perspectiva de que a Didática da História estuda a consciência histórica em todas as suas formas, compõem a base da proposição de uma "didática da história ampliada" (SADDI, 2012). Neste mesmo texto, Saddi identifica as quatro reduções que cumprem contestar para a atualização do conceito de Didática da História: redução à técnica de ensino, redução à escola, redução a um campo externo à História, e redução a uma área técnica de formação profissional (SADDI, 2012, p. 212).

Seguindo a trilha de identificar primeiro o que a Didática da História não é, podemos contribuir com a ideia de que a Didática da História, como estamos traçando aqui, não é uma escola ou uma tendência dentro do campo conhecido tradicionalmente como "ensino de história". Assim, não seria uma designação na mesma categoria que "educação histórica", no sentido de um "campo" ou de um "domínio teórico" particular (CAINELLI; SCHMIDT, 2012, p. 509). Nesse sentido, não entendemos a Didática da História como uma escola ou uma vertente dentro dos estudos que abrangem o sentido amplo de ensino de História. Em vez disso, Didática da História é o nome que se dá à disciplina que congrega os estudos em ensino de História, à falta de melhor designação, envolvendo a perspectiva 
ampliada de que fala Rafael Saddi (2012): ultrapassa a limitação de seus objetos à metodologia de ensino, à escola, ao exílio em relação à História e à formação do professor de História. "Ultrapassa" não quer dizer abandona. Ao invés disso, reivindica que a compreensão de cada uma dessas categorias ou frentes de intervenção só se dá ao consideramos o contexto mais amplo em que se inserem. Exatamente o "mandamento" que emerge de todas as crises que se relacionam com a mudança de paradigmas do ensino da História.

Não é porque os autores alemães dessa discussão descrevem e teorizam, de forma acurada, e identificam a mudança paradigmática, que eles deveriam ditar o temário e a metodologia da disciplina. Reconhecer a Didática da História, em sua configuração contemporânea, não significa adesão a Rüsen, Pandel, Jeissman, Bergmann, e outros, como referência única ou mesmo principal, na mesma proporção que ser antropólogo, por exemplo, não é ser seguidor de Margaret Mead ou Clifford Geertz: ser antropólogo é não desconhecer Mead ou Geertz em suas contribuições fundamentais para a constituição ou o desenvolvimento da disciplina.

Por fim, somando ao esforço de definição da Didática da História, pode-se traçar, abaixo, alguns elementos do que essa disciplina é ou pode ser.

Exatamente por se tratar do resultado de uma ultrapassagem de limites, e da necessidade de inserir a reflexão sobre o ensino de História nos contextos mais amplos, é que se trata de um campo fronteiriço da pesquisa histórica e, por isso, é limitador entendê-la como disciplina que se assenta dentro dos limites disciplinares da História. O conjunto de fenômenos sobre os quais ela é convocada a debruçar-se não pode ser enfrentado apenas com os instrumentos da pesquisa histórica, nem equacionados teoricamente apenas com os recursos da Teoria da História.

Em favor do equilíbrio da definição, por outro lado, é importante destacar que não se pode compreender a Didática da História isoladamente da ciência histórica. Pelo contrário, todo historiador é didata da História em alguma medida, da mesma forma que é teórico da História, em alguma medida, embora essas possam não ser suas frentes privilegiadas de ação e produção. A reflexão didática, como a reflexão teórica, são componentes indissociáveis do pensamento histórico, definido ad hoc como a identidade do historiador, em termos de sua competência (por sua vez no duplo sentido de capacidade e de atribuição). 
A disciplina Didática da História está composta de várias vertentes, perspectivas, enfoques, abordagens, pontos de partida teóricos e preocupações. Trata-se de um objeto mais comumente definido como "ensino de História" (como em "Encontro de Pesquisadores do Ensino de História", mas não em "Encontro Perspectivas do Ensino de História"), com a vantagem de ser menos equívoco. "Ensino de História" é uma categoria mais ampla do que "Didática da História" no sentido que aqui estamos construindo que, por sua vez, engloba escolas ou campos com teorias, objetos e metodologias mais bem delimitados, como "educação histórica". Porém, "ensino de História", conforme o contexto, pode ser o equivalente de "Didática da História", como vimos, ao descrever um campo disciplinar de estudos (como ocorre, por exemplo, nas linhas de pesquisa em ensino de História de programas de pós-graduação em História e em Educação). Não tivesse sido apropriado por uma escola específica, o termo "educação histórica" seria uma forma mais apropriada de referir-se ao fenômeno social e educacional que chamamos comumente de "ensino de história", termo que por sua vez é limitado ao trazer à tona apenas um dos aspectos da educação, o ensino, velando o aspecto fundamental da aprendizagem. De fato, em publicações estrangeiras, o termo "history education" corresponde ao conceito que temos de "ensino de história" e não, necessariamente, aos estudos delimitados pela escola da educação histórica (ver CERRI, 2014).

Em suma, a Didática da História, como disciplina fronteiriça da ciência histórica, é caracterizada por:

a) Objeto de estudo ampliado em relação ao paradigma anterior, que a restringia aos métodos e técnicas de ensino escolar de História. A Didática da História, para rastrear as produções, os fluxos de distribuição, cruzamentos e choques de conhecimentos históricos, sua recepção, decodificação e usos, parte de um conceito amplo de conhecimentos históricos. Toda narrativa, verbal ou imagética, prolixa ou abreviada, nome ou texto que estabelece sentidos para o tempo e a identidade de indivíduos e grupos é reconhecida como a história em sentido amplo. O entendimento de seus contextos de produção, distribuição e consumo, convergência e confrontos, é condição para decifrar a aprendizagem histórica escolar e extraescolar, entendida como fenômeno significativamente autônomo do ensino. Esses objetos são favorecidos pelo conceito de cultura 
histórica como expressão visível da consciência histórica (RÜSEN, 1994) em sua diversidade individual e social.

b) Referência à Teoria da História e aos campos da Educação, Psicologia (Social, da Aprendizagem), Sociologia, Antropologia etc. Como a Didática da História lida com um amplo conjunto de objetos, obriga-se a não apenas dialogar com ciências e disciplinas próximas como adaptar e aproveitar perspectivas teóricas e metodologias de pesquisa. A ciência privilegiada neste diálogo é, evidentemente, a Educação, com particular interesse no campo do ensino e aprendizagem; o fato da Didática da História ter sido reduzida - por concepção tradicional da História e do ensino - à técnica de ensino, não conduz a que abandone hoje a preocupação e o trabalho com a metodologia de ensino, e os aportes de uma Pedagogia em contínuo avanço, no conhecimento e nas proposições para o ensino e a aprendizagem.

c) Produção de levantamentos empíricos sobre ensinos e aprendizagens, que assumem forma de reflexão didática. O fato de ser uma disciplina a um tempo interna e fronteiriça à História não implica, necessariamente, que produza uma historiografia, ou seja, uma narrativa argumentada e fundamentada sobre um determinado fenômeno no tempo. Nisso, tem um estatuto histórico similar à Teoria da História, ou seja, produz texto e conhecimento internos à História, mas não necessariamente historiográficos. Entretanto, a Didática da História não é avessa ou incompatível com a prática historiográfica: quando se dedica a historiografar, aproxima-se da História da Educação (história do Ensino de História) e das perspectivas da História recente e imediata. Seu objeto, em geral, não se estende no tempo, mas é capturado no presente, a partir do que se sabe, do que se aprende ou do que se ensina (dentro ou fora da escola, voluntária ou involuntariamente) hoje. Evidentemente, o que se apreende do hoje tem uma profundidade temporal que não é ignorada pelo pesquisador, mas não é seu foco primário. A intenção está concentrada em identificar como esta profundidade temporal se expressa na atualidade, como estão se dando as relações de produção, difusão, negociações e utilização dos conhecimentos históricos.

d) Construção metodológica que não se atém aos cânones do método histórico, embora não o perca de vista. Pelo que se deduz do tópico anterior, o produto da Didática da História não tem que seguir o modelo usual de recorte 
cronológico do tema escolhido, seguido de levantamento ou produção de fontes sobre o tema dentro do recorte, análise interna e externa das fontes coligidas, interpretação e redação. Fora desse roteiro (ou similares) e ainda fazendo História, pode ser uma pesquisa de caráter educacional (avaliação da aprendizagem em sala de aula, laboratório de aprendizagem, observação em sala de aula), sociológico (pesquisa quantitativa tipo survey, pesquisa qualitativa sobre representações sociais, análise de dados quantitativos já postos, como resultados do ENEM, ENADE, etc.), ou mesmo clínico (autoanálise do professor sobre suas intervenções em sala de aula) (ZAVALA, 2012) entre vários outros.

O eixo comum que mantém as pesquisas em Didática da História na História ou em sua órbita mais baixa é a racionalidade histórico-científica: historicidade das coisas, a fundamentação dos enunciados dentro do atual estágio do saber histórico, a validade do melhor argumento etc.

\section{Concluindo: Possibilidades da Didática da História na pesquisa histórica (ou: porque os objetos da Didática da História podem e devem servir em instituições e programas de pesquisa histórica)}

Tomemos como primeiro exemplo de um resultado de pesquisa em Didática da História os dados contidos no gráfico 1. Trata-se da síntese de uma das questões do levantamento "Os Jovens e a História no MERCOSUL", que usou um questionário fechado e metodologia de análise estatística descritiva para avaliar aspectos do ensino e aprendizagem históricas, no Brasil e outros países da América do Sul, com uma amostra que girou em torno de 4 mil estudantes em diversas cidades e tipos de escola.

O dado capturado refere-se à preferência média de jovens estudantes de 15 e 16 anos quanto a 6 diferentes períodos da história. Embora o resultado tenha sido construído ao longo de décadas de vivência de diferentes gerações na cultura histórica, que vai dos filmes no cinema às séries de televisão, passando por jogos eletrônicos, livros e aulas de História na escola. Mas esse processo, pela sua amplitude, extensão e quantidade de componentes ou variáveis, dificilmente poderia ser abrangido por uma pesquisa histórica, e nem foi esse o objetivo. 0 
objetivo buscado, e a nosso ver atingido, foi o de radiografar um aspecto da cultura histórica - e em parte também cultura escolar - dos jovens.

Gráfico 1 - Médias nacionais de respostas à questão: "qual o seu interesse nos seguintes períodos da história". *

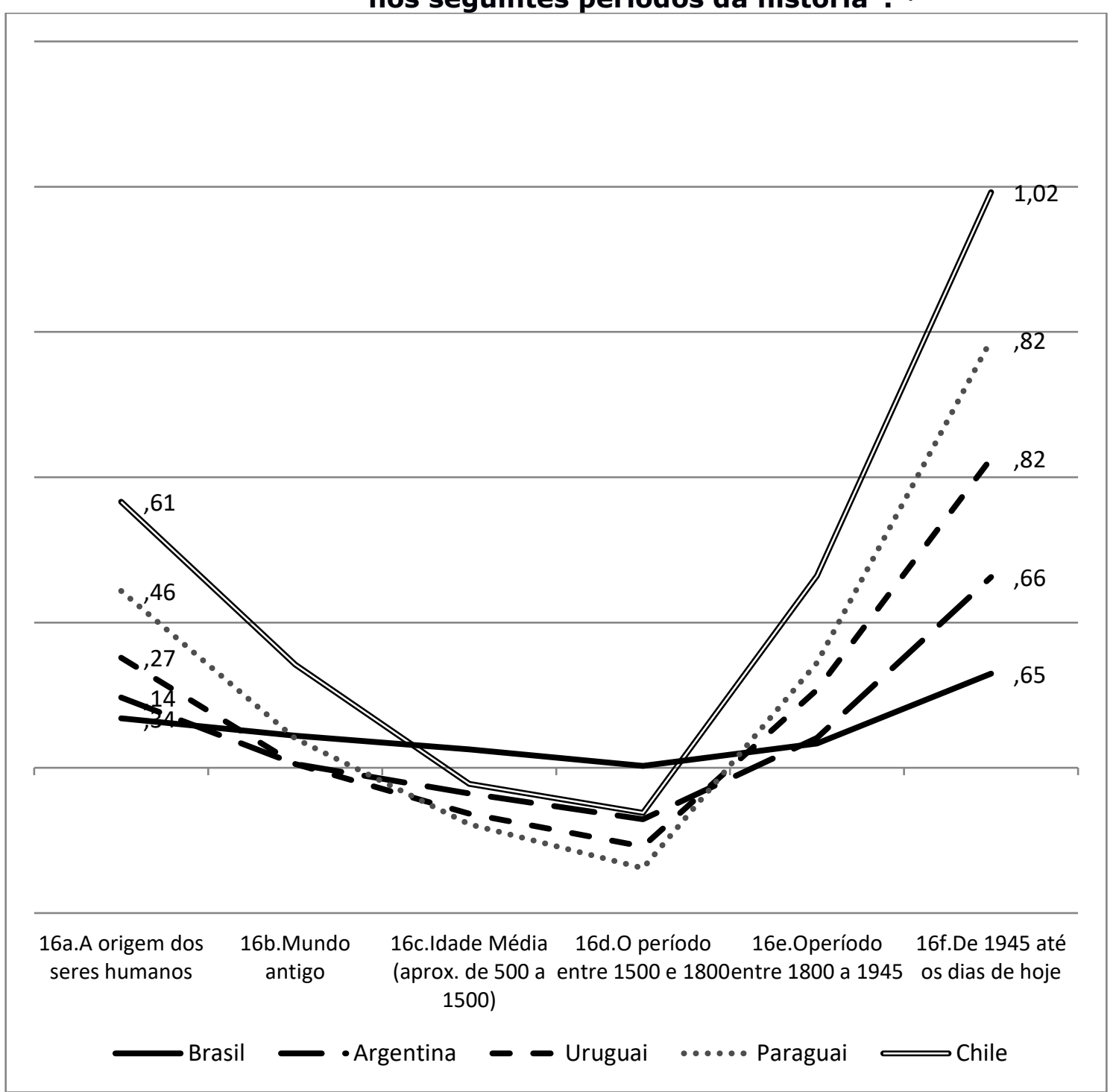

Fonte: Dados organizados pelo autor com base no Projeto Jovens e a História (2013).

* Respostas na Escala Likert com as médias variando entre -2 (=não me interesso) a 2 (= me interesso muito). $\mathbf{N}=3.913$, sendo 2420 do Brasil, 965 da Argentina, 227 do Uruguai, 119 do Paraguai, e 182 do Chile.

Algumas conclusões breves podem ser deduzidas desse gráfico, assim como novas questões podem ser propostas a partir de seus resultados. Por exemplo, as médias de interesse em cada período histórico naturalmente variam de país para país, mas a inter-relação entre as médias de interesse em cada país (ou seja, o 
desenho da linha formada pela união dos pontos que as representam) é igual em todos os países. Ou seja, os tempos pré-históricos e a atualidade são, em todos os casos pesquisados, os períodos de maior interesse assim como o período moderno é o ponto de menor interesse, em média. O dado produzido, enfim, dá uma notícia, um panorama que resulta da conjunção de alguns fatores ao longo do tempo: o resultado da ação dos professores de História, dos conteúdos históricos nos círculos de convivência dos estudantes e dos produtos de mídia ao alcance dos estudantes, com os quais estes vêm a interagir.

De certa forma, o desenho das linhas é um dado produzido a partir de uma pesquisa empírica de caráter quantitativo, mas que reflete outro dado com o qual, aparentemente, não teria conexão alguma: a concentração de estudos, publicações e interesses de pesquisa nos departamentos e faculdades de História, pelo menos no Brasil. O desenho, muito provavelmente, guarda relação com os interesses de pesquisa dos historiadores no Brasil - como o meio em que vivemos é a cultura histórica, que nos forma historiadores, antes, durante e depois de nossa profissionalização como historiadores. Esse tipo de dado coloca em tela uma reflexão teórica sobre a produção do conhecimento histórico, em termo de seus condicionantes: assim, o trabalho da Didática da História também pode desempenhar um papel epistemológico para a História e a historiografia, mas em termos de uma epistemologia voltada "para fora" da ciência, em vez de "para dentro", como é comum nos estudos de Teoria da História.

Outro elemento que o exemplo permite destacar é que o tipo de produção histórica da Didática da História tem um braço de pesquisa empírica muito mais destacado do que a Teoria da História, mas trata-se de uma pesquisa que pode ser - e geralmente é - muito diferente da pesquisa historiográfica e do seu trabalho com documentos. É um trabalho distinto também da Teoria da História que, em certo grau, também se relaciona com uma empiria, ou seja, tem como fontes os resultados dos textos de historiografia. Em vez disso, a Didática da História lida com resultados da historiografia sobre o mundo atual, além do resultado de outros focos de emissão de conteúdos, discursos e juízos históricos sobre o mundo em que vivemos, que se cristalizam na forma das várias manifestações de cultura histórica. 
A Didática da História vale-se de diversas metodologias para o estudo da cultura histórica que podem, às vezes, ser tão pouco usuais, e um olhar desatento imaginará que tal pesquisa não é pesquisa histórica, mas educacional, sociológica, curricular, antropológica. Ela certamente será um pouco disso, ou tudo isso, mas também uma pesquisa histórica: pode ser que faça uma volta grande e passe por diversos domínios "estrangeiros", mas o que a torna histórica, e faz com que permaneça assim, é que ela sempre partirá (nas perguntas) da História, e retornará (nos resultados, encaminhamentos e novos questionamentos) da História. Cabe à História, encarnada nos historiadores, decidir se querem juntar às suas riquezas, as especiarias, sedas e preciosidades que esses viajantes trazem, às vezes junto com a simplicidade, a rudeza e o pó da estrada que os acompanham.

\section{Referências}

ANGVIK, Magne; Von BORRIES, Bodo (Ed.) Youth and history: a comparative european survey on historical consciousness and political attitudes among adolescents. Hambourg: Edition Körber-Stiftung, 1997. v. A.

BERGMANN, Klaus. A história na reflexão didática. Revista Brasileira de História, São Paulo, v. 9, n. 19, p. 29-42, 1990.

BITTENCOURT, Circe Maria Fernandes. Os confrontos de uma disciplina escolar: da história sagrada à história profana. Revista Brasileira de História. São Paulo, v. 13 n. 25/26, p. 193-221, set.1992/ago. 1993.

BRUTER, Annie. L'histoire enseignée au grand siècle. Naissance d'une pédagogie. Paris: Belin, 2003.

CAINELLI, Marlene; SCHMIDT, Maria A. Desafios teóricos e epistemológicos na pesquisa em educação histórica Antíteses. Londrina, v. 5, n. 10, p. 509-518, jul./dez. 2012.

CARDOSO, Oldimar. Para uma definição de didática da história. Revista Brasileira de História, São Paulo, v. 28, n. 55, p. 153-170, 2008.

CERRI, Luis Fernando. Entrevista com o Prof. Dr. Luís Fernando Cerri (UEPG). Revista de Teoria da História, Goiânia, v. 6, n. 12, p. 369-391, 2014.

CITRON, Suzanne. Le Mythe Nacional. Paris: Ouvriéres, 1987. 
CITRON, Suzanne. Enseigner L'Histoire Aujourd'hui. la mémoire perdue et retrouvée. Paris: Ouvriéres, 1984.

CUESTA FERNANDEZ, Raimundo. El código disciplinar de la historia. Tradiciones, discursos y prácticas sociales de la educación histórica en España (siglos XVIIIXX). 1997. Tese (Doutorado) - Universidad de Salamanca, Salamanca.

FONSECA, Selva Guimarães. Caminhos da história ensinada. Campinas: Papirus, 1993.

FONSECA, Thais N. de L. Ver para compreender: arte, livro didático e história da nação. In: SIMAN, Lana M. C.; FONSECA, Thais N. de L. Inaugurando a história e construindo a nação: discursos e imagens no ensino de história. Belo Horizonte: Autêntica, 2001.

FURET, François. O nascimento da história. In: A oficina da história. Lisboa: Gradiva, 1986.

GASPARELLO, Arlette M. Construtores de identidades: a pedagogia da nação nos livros didáticos da escola secundária brasileira. São Paulo: Iglu, 2004.

MATTOS, Selma R. de. O Brasil em lições: a história como disciplina escolar em Joaquim Manoel de Macedo. Rio de Janeiro: Access, 2000.

PACIEVITCH, Caroline; CERRI, Luis Fernando. Professores progressistas de história e a pedagogia histórico-crítica nos anos 80: aproximações e distanciamentos. Revista História Hoje, São Paulo, v. 3, n. 9, abr. 2006. Disponível em: <www.anpuh.org/arquivo/download?ID_ARQUIVO=74>. Acesso em: 10 jun. 2016.

RABELO, Alberto Coutinho. O lugar de Carlos Gomes na formação social da música brasileira. 2013. Dissertação (Mestrado) - Universidade Federal de São Paulo, Escola de Filosofia, Letras e Ciências Humanas, Guarulhos, 2013.

RÜSEN, Jörn. Reconstrução do passado: teoria da história II: os princípios da pesquisa histórica. Tradução de Asta-Rose Alcaide. Brasília: Editora UnB, 2007a.

RÜSEN, Jörn. História viva. Teoria da história III: formas e funções do conhecimento histórico. Trad. Estevão de Rezende Martins. Brasília: Editora da Universidade de Brasília, 2007b.

RÜSEN, Jörn. Didática da história: passado, presente e perspectiva a partir do caso alemão. Práxis Educativa, Ponta Grossa, v. 1, n. 2, p. 7-16, 2006.

RÜSEN, Jörn. Razão histórica: teoria da história: os fundamentos da ciência histórica. Tradução de Estevão de Rezende Martins. Brasília: Editora da UnB, 2001.

RÜSEN, Jörn. ¿Qué es la cultura histórica? Reflexiones sobre una nueva manera de abordar la historia. In: FÜSSMANN, K.; GRÜTTER, H. T.; RÜSEN, J. (Ed.). Historische faszination: geschichtskultur heute. Weimar: Böhlau, 1994. p. 3-26. 
SADDI, Rafael. Didática da história na Alemanha e no Brasil: considerações sobre o ambiente de surgimento da Neu Geschichtsdidaktik na Alemanha e os desafios da Nova didática da história no Brasil. Opsis, Catalão-GO, v. 14, n. 2, p. 133-147, jul./dez. 2014.

SADDI, Rafael. O parafuso da didática da história: o objeto de pesquisa e o campo de investigação de uma didática da história ampliada. Acta Scientiarum Education. Maringá, v. 34, n. 2, p. 211-220, jul./dez., 2012.

WILLIANS, Raymond. Marxismo e literatura. Rio de Janeiro: Zahar, 1979.

ZAVALA, Ana. Mi clase de historia bajo la lupa. Por un abordaje clínico de la práctica de la enseñanza de la historia. Montevideo: Trilce, 2012.

Recebido em 07 de fevereiro de 2017

Aprovado em 22 de agosto de 2017 